\title{
Informal Science Education in the Footsteps of Galileo's Dialogue
}

\author{
Constantina Stefanidou', Maria Panagopoulou ${ }^{2}$ \\ ${ }^{1}$ Department of Education, National and Kapodistrian University of Athens, Athens, Greece \\ ${ }^{2}$ Department of Physics, National and Kapodistrian University of Athens, Athens, Greece \\ Email: sconstant@primedu.uoa.gr
}

How to cite this paper: Stefanidou, C., \& Panagopoulou, M. (2019). Informal Science Education in the Footsteps of Galileo's Dialogue. Advances in Historical Studies, 8 , 175-191.

https://doi.org/10.4236/ahs.2019.85013

Received: July 15, 2019

Accepted: November 3, 2019

Published: November 6, 2019

Copyright ( 2019 by author(s) and Scientific Research Publishing Inc. This work is licensed under the Creative Commons Attribution International License (CC BY 4.0).

http://creativecommons.org/licenses/by/4.0/

\begin{abstract}
In this paper, the inclusion of History and Philosophy of Science in non-formal and informal science education is proposed in order to provide students with the opportunity to grasp some aspects of Nature of Science with which they are not familiarized in the context of formal education. The cultural aspects of science, which is an important component of scientific literacy, are presented in an informal education context: in this case, a Science Festival. An interactively narrative inspired by Galileo's Dialogue is used in order to engage junior high school students with History of Science and to enhance their conceptual understanding of cultural aspects of science.
\end{abstract}

\section{Keywords}

Galileo, Science Festival, Informal Science Education

\section{Introduction}

History and Philosophy of Science (HPS) in science teaching has a long history. The main arguments for its inclusion are that HPS fosters a deeper understanding of: 1) the subject matter, meaning that the History of Science (HOS) may reveal the important context of the fragments of knowledge in question; 2) how learning in science education relates to the growth of scientific knowledge; and 3) the Nature of Science (NOS), in terms of methodological, philosophical and cultural aspects of science (Matthews, 2015; Stefanidou \& Skordoulis, 2014; Stefanidou \& Skordoulis, 2017).

The goal of science education globally today is scientific literacy. Along with other ideas about science, scientific literacy implies that students should have a concrete idea of "how science works". Learning "how science works" means teaching and learning scientific practices, some of them which will result in er- 
roneous results. In other words, "how science works" is strongly related to "how science does not work". HPS provides us with numerous historical cases which illustrate that science is fallible, contingent and provisional. Studying certain historical episodes fosters the students' understanding not only of the suggested scientific practices, but also of what can go wrong in science (Allchin, 2012). Scientific controversies are a way of introducing students to real-life scientific situations and allowing them to take the initiative in believing some things to be true and others erroneous.

The HOS has been recommended by many educators as a way of motivating students to learn subjects regarded as difficult, changing the public perception of scientists, encouraging informed participation in decisions about the uses to which technology is put, and conveying an appreciation of science as an element of culture. These issues have arisen in the context of growing concern about the quality and effectiveness of education (Brush, 1989). Furthermore, it is widely believed that individual learning histories in science tend to mirror the historical development of scientific concepts (Hodson, 2008). It is thus logical to argue that knowledge of the historical development of a scientific discipline can help teachers as much as students, since they can anticipate, understand and deal with any conceptual difficulties and misconceptions, their students might have more easily (Sequeira \& Leite, 1991; Hodson, 2008). The historical approach is both intriguing and comforting: it helps students to discover that eminent scientists of the past held views similar to their own, even if these views were later shown to be incorrect (Hodson, 2008). HOS also forces students to engage with the origins of our knowledge, the reasons it may be accepted or rejected, and the impact of certain scientific theories and ideas on the culture in which it arose (Cassidy et al., 2002).

In the extensive literature review undertaken by Seroglou \& Koumaras (2001), research papers related to HPS in science education conducted between 1893 and 2000 are categorized. Three main dimensions emerged: the cognitive, the metacognitive and the emotional; two further categories relate to, respectively, curricula development and teacher education. The research revealed that since 1965 , there has been a gradual shift in the focus of research interest from the cognitive to the metacognitive. Such a shift parallels the discussion on the teaching of the NOS and the relationship between science and society.

Chasapi (2018) in her thesis recorded and categorized published research papers from 2000-2017 relating to the role of HPS in science education. The study confirmed previous results regarding the dominant role which HPS plays in teaching the cultural and methodological aspects of science, and shed light on other aspects of the relationship between HPS and science education, such as the fact that most published research stems from secondary education, with primary and higher education less active in the field. This raises the issue of science teacher education on HPS topics, which is integral to the integration of HPS into science classes. Another finding of Chasapi's (2018) research is the fact that the 
overwhelming majority of proposals focus on formal science education, at both the level of practice and of curriculum design. Very few of the proposals relate to the role of HPS in informal and non-formal science education, meaning science as it is presented in museums, theatres, films, science festivals and popular science books. Filippoupoliti \& Koliopoulos, too, mention that the study of the role of the HOS in informal and non-formal science education is heterogeneous and fragmentary and find a need for new research questions to be raised and new lines of research constructed to investigate the subject in a more systematic way. This suggests a need to conduct research into the integration of HPS into activities outside the organized educational system; for instance, we are aware of the value of museums visits, in terms both of knowledge content and of motivating and fostering positive attitudes towards the natural sciences (Filippoupoliti \& Koliopoulos, 2014).

Regarding the research field in Greece, Skordoulis \& Stefanidou (2011) in their paper "Epistemological Aspects of the Historiography of Science in Greece", present the context in which History and Philosophy of Science and Science Teaching (HPST) developed in Greek academia.

It is a firm belief for scholars in the Department of Primary Education of the National and Kapodistrian University of Athens that only a process of systematic teacher education and training on both undergraduate and postgraduate level in history, epistemology and didactics of science linked with research work on the conditions that have shaped the educational environment from the 19th century onwards and in constant dialogue with the international community holding similar views can create fertile ground for the success of the HPST Program.

The present study is developed within this framework and its purpose is, after almost twenty years of research activity to formal education, to expand the role of history and philosophy of science in informal and non-formal science education. To this end, our aim here is to draw attention to the role that HPS could play in informal and non-formal education, and particularly in the context of the Athens Science Festival, which is an important and established event in Greece. This study has the characteristics of a case study and aims at broadening the role of HPS in informal and non-formal science education. In this context, an interactive dialogue was designed and presented which follows the steps of Galileo Galilei and his book Dialogue Concerning the two chief world systems (Dialogue).

In Section 2, informal and non-formal educations are presented with a focus on their possible contribution to formal science education and general scientific literacy. In Section 3, we briefly present the Science Festival as an emerging institution, while in Section 4, the role of HPS in informal and non-formal education (primarily in science museums and science centers) is presented. Section 5 is devoted to Galileo Galilei and the Dialogue, for the writing of which he found himself before the Inquisition. In Section 6, the educational program is presented and discussed. Section 7 presents the implications for further research. 


\section{Formal, Non-Formal and Informal Science Learning: Towards a Synthesis}

Out-of-school learning can be divided into two categories: non-formal and informal education. Informal education is completely spontaneous and can occur everywhere, while non-formal learning is planned and mediated by formal education, but the motivation for learning may be wholly intrinsic to the learner (Eshach, 2007). Particularly, informal learning results from daily life activities related to work, family or leisure, e.g. watching a documentary. It is not structured, in terms of learning objectives or learning time and typically does not lead to certification. Regarding non-formal learning, it includes various structured learning situations, such as professional seminars or educational visits to museums, which do not either have the level of curriculum, syllabus, accreditation and certification associated with formal learning, but have more structure than that associated with informal learning, which typically take place naturally and spontaneously as part of other activities. In practice, we could discern little difference between informal and non-formal learning. The two terms usually appear interchangeably, each being primarily defined in opposition to the dominant formal education system (Malcolm et al., 2003). In this context, informal education is referred to as either informal or non-formal education. Moreover, Malcolm et al. (2003) claim that formal education bears some kind of informality and vice versa, but they do not claim that learning is the same in all situations: learning in the workplace is different from learning in school. Rather, they emphasize the difficulty and uncertainty involved in classifying learning into three types_formal, non-formal and informal learning_-given that pedagogical tools, processes and settings may be used in all three. Such an argument initiates a conversation on the impact of informal and non-formal on formal learning and vice versa.

To understand fully children's science learning, one should look not only at learning that takes place in school but also at learning that takes place out of school. Children's life experiences both in and out of school have a profound impact on how well they perform both in school and in society. Support for the importance of informal experiences can be found in the National Science Education Standards (National Research Council, 1996), which state that museums and science centers "can contribute greatly to the understanding of science and encourage students to further their interests outside of school" (p. 45).

To more fully understand the importance of incorporating out-of-school learning, it is crucial to bear in mind the unfortunate fact that schools alone have not usually been successful in creating scientifically literate citizens (Fensham, 1997). This paper will argue that students' lifelong interest in and understanding of science may be improved by the provision of out-of-school science experiences. In Kroto's words: “Unless the young people of the twenty-first century appreciate the importance of science, we stand no chance whatsoever of economic, social or cultural survival. In my view, science museums and science 
centers must play an appropriately active part in the educational program on which this survival depends (Kroto, 1997, joint winner of the 1996 Nobel Prize for chemistry).

\section{Science Festivals}

The history of science festivals can be traced back to the British Association for the Advancement of Science's annual conference. This event was founded in 1831 to encourage discussion between scientists and other learned men with a view to promoting scientific progress (British Science Association, 2019). Thanks to the efforts of the Association, public lectures, discussions and demonstrations of research were held, and science gained in popularity as a result. During these events, the concept of scientist (scholar) was formulated for the first time, the word dinosaur entered public discourse (1842), and the first public debate about Darwinism was held (1860). The annual conference was renamed the Festival of Science in the 1980s and is now the British Science Festival (Jensen \& Buckley, 2012). In the 20th century, science festivals have been held in many European countries as well as in the United States, Canada, and China.

Regarding Greece, since its launch in 2014, the Athens Science Festival has established itself as one of the country's most important celebrations of science and technology. For one week every spring, school children and other visitors from the greater Athens area take the opportunity to explore science in innovative, interactive and enjoyable ways, while researchers, teachers, distinguished scientists, artists and performers do their very best to communicate science and make it part of their audience's everyday lives (Figure 1). In addition, other similar events have now emerged, including the Thessaloniki Science Festival (since 2015) and the Patra Science Festival (since 2017), which are staged by "Science Communication-SciCo", an educational organization, as well as by the British Council and various research and educational institutes.

Contemporary science festivals tend to bring together temporary exhibits, museum activities, scientists, arts organizations, school children and publics to create time-limited special events. Science festivals may be managed by different types of organization, including science museums and centers, universities, independent
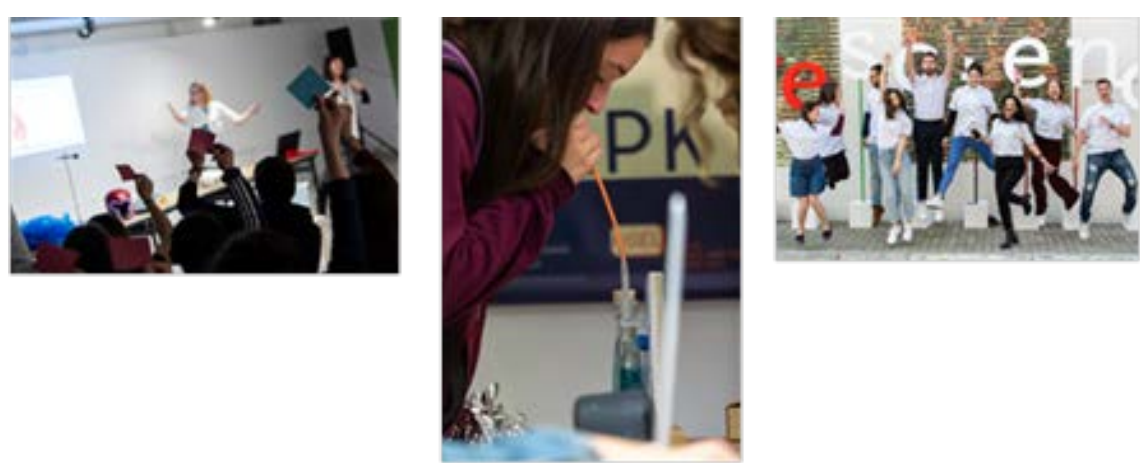

Figure 1. Activities of the department of education of the national and Kapodistrian University of Athens during the Athens Science Festival, on $4^{\text {th }}$ April 2019. 
charities, research councils, and agencies funded by local or central government (EUSCEA, 2005).

Science Festivals have rapidly expanded in size and number in recent years (Jensen \& Buckley, 2012; Riise, 2012). They are increasingly prevalent within the broader spectrum of informal science engagement events internationally. Basically, the term "science festival" covers any public event where science is presented to the public. Initially the festival part referred to these events' similarity to arts, film, or music festivals but with science as the main content (Riise, 2012). Science festivals tend to differ from activities provided by science museums and centers, due both to their temporary nature and their focus on current scientific research. Festivals usually offer a wide range of potential experiences within the time-limited festival context: visiting audiences have the possibility to attend and participate in debates and discussions presenting a range of view-points, and to have access to a more authentic and in-the-making form of scientific knowledge than the ready-made science that science advocates may wish to display (Jensen \& Buckley, 2012). Raising public awareness of science and technology is often the most important reason for organizing an event (Riise, 2012). It has been shown that the visitors value the opportunities the science festival provides to interact with scientific researchers and encounter different types of science engagement aimed at adults, children and families. The most significant self-reported impact of attending a science festival is the emergence of an increased interest in and curiosity about new areas of scientific knowledge in a socially stimulating and enjoyable setting (Jensen \& Buckley, 2012). Usually, the topics and activities that take place at science festivals are inspired by the most recent technological and scientific discoveries and by environmental problems. There are also many hands-on activities and impressive demonstration experiments.

Apart from presenting high quality scientific research, science festivals also connect science with everyday life, inspire and create new standards in the scientific field, and encourage young people to consider a career in science by providing pleasant experiences in a scientific context. Another goal of the science festival is to promote, both to young and old visitors, cultural aspects of science such as its role in society, and to showcase historical debates on complex and controversial scientific issues.

\section{The History and Philosophy of Science in an Informal Science Education Environment}

HPS has a prominent presence as an exhibition theme found in different types of science museums and in science centers. According to Filippoupoliti's \& Koliopoulos' (2014) review, during the 1980s important changes occurred in the ways museum curators displayed the HOS in exhibitions. At least three epistemological approaches can be identified in museum exhibitions: The first, traditional, approach treats the HOS as the documentation of objects and facts. The second treats the HOS as a history of ideas and is now broadly used to weave a narrative into a science exhibition. In this case, the authenticity of the science 
collection (i.e. whether the scientific instruments are historic or reconstructions) is of minor importance. The emphasis here is to how an idea (or ideas) is born, and how it is subsequently developed and cognitively treated to give meaning to objects. For example, the Grande Galerie de I Evolution of the Muséum National d Histoire Naturelle in Paris focuses on the evolution of species (Van Praet, 1995). Exhibitions belonging to these first two categories seek to disseminate the content, the process and the product of science from an internal point of view: the viewpoint of science. In contrast, the third approach considers trends in the HOS literature that view science as an example of culture, with particular practices and tools affected, developed and transformed according to the cultural and historical context in which they emerge, including non-scientific factors (Golinski, 1998; Galison \& Thompson, 1999; Daston, 2000).

Filippoupoliti \& Koliopoulos' (2014) review of the educational tools used by museums to communicate HOS elements also identified three categories of educational material:

1) Guided tours focused on narratives from the HOS: Unlike formal education, during a guided tour of a museum, the guide cannot expand on the narration to explain a topic in detail. In this context, guided museum tours using narratives from the HOS are the weakest type of educational program for presenting the history of science.

2) Museum educational programs and workshops: Educational programs are structured educational environments designed to acquaint students and teachers with scientific and historical knowledge in a systematic way.

3) Collaborations between museums and formal education: many researchers have argued that the collaboration between school and museum can promote the achievement of both cognitive and emotional student outcomes.

Apart from science museums and science centers, HPS has also a prominent role to play in the theatre. Science and its socio-political milieu form the core of plays including The Life of Galileo by Berthold Brecht, Copengagen by Michael Frayn, and Physicists by Friedrich Durrenmatt. In these plays, several episodes from HPS are presented by the writers who, adopting a critical view, reveal cultural aspects of science that do not figure frequently in schoolbooks and formal education. Moreover, numerous films related to the history of science have been made including Einstein's big idea (2005, dir. G. Johnstone), the theory of everything (2014, dir. J. Marsh), and Inherit the Wind (1960, dir. S.Kramer), which focus on cultural and methodological aspects of science. Documentary films about HOS offer fruitful material for younger and adult audiences, while informative and ambitious series such as The Story of Science (M.Mosley, BBC) are gaining ground in television programming in Europe.

Is it possible for HPS to be more interactive and thus more attractive for students and lay people fostering positive attitudes towards science? Science festivals are structured to offer opportunities for visitors to have memorable positive experience. This is the contribution of the present paper, in which a Science Festival activity based on HOS is proposed and presented: specifically, an interactive 
narrative inspired by an authentic historical book, Galileo's Dialogue Concerning the two chief world systems. The next section will discuss the primary source, Galileo's Dialogue.

\section{Galileo Galilei and His Dialogue Concerning the Two Chief World Systems}

Galileo's Dialogue ranks high among the classics of science and is deservedly even more famous as a chapter in the struggle for freedom of thought. It is a mine of information for anyone interested in the cultural history of the Western world and its influence on economic and political development (Einstein, 1953/2001). Einstein, in his foreword to Dialogue, presented Galileo as representing rational thinking in the face of a horde of those who, relying on the ignorance of the people and the indolence of teachers in priest's and scholar's garb, maintain and defend their positions of authority. In advocating and championing Copernican theory, Galileo was not only motivated by efforts to simplify the representation of the celestial motions. His aim was to replace a petrified and barren system of ideas with an unbiased and strenuous quest for a deeper and more consistent comprehension of the physical and astronomical facts.

His extraordinary literary gift enables him to address the educated men of his age in such clear and impressive language that he overcomes the anthropocentric and mystical thinking of his contemporaries and leads them back to an objective and causal attitude toward the cosmos-an approach which had become lost to humanity with the decline of Greek culture (Einstein, 1953/2001). The Platonic dialogue he uses in the work enables Galileo to apply his extraordinary literary talent to a sharp and vivid confrontation of opinions. Galileo's Dialogue addresses the public, rather than a specific group of intellectuals-which is also why it was one of the first books to be written in Italian rather than Latin, the official language used for scientific articles (Cassidy et al., 2002; Karolides et al., 2011; Drake, 1973). Galileo abandoned Latin in favor of Italian as early as 1612; in that year, writing to a friend about an earlier book, he said: "I wrote the book in the vernacular because I want everybody to be able to read it" (Drake, 1957: p. $84)$.

Using the dialogue form, Galileo masterfully demonstrates the truth of the Copernican system over the Ptolemaic one, proving that the Earth revolves around the Sun. Galileo wanted to avoid openly committing himself on these controversial questions, which would have delivered him into the hands of the Inquisition. Galileo had, in fact, been expressly forbidden to advocate the Copernican theory. Apart from its revolutionary factual content, the Dialogue also represents a downright roguish attempt to seem to be complying with this order while actually disregarding it completely. Unfortunately, it turned out that the Holy Inquisition was unable to adequately appreciate such subtle humor (Einstein, 1953/2001). Indeed, Galileo's ability to write in a witty, sarcastic, informative and profound way made him a particular threat to the Church.

Galileo casts the work as a literary dialogue among three interlocutors: Salvia- 
ti, who in essence spoke for Galileo; Sagredo, who represented the interested, intelligent amateur; and Simplicio, the "simpleton" who staunchly voiced Aristotelean views. The action unfolds over four days. On day 1 , using evidence concerning the moon and other new telescopic discoveries, Galileo develops a devastating critique of traditional Aristotelian notions of place, motion, up and down, and the venerable distinction between the heavens and the earth. On day 2 , he treats the earth's daily rotation on its axis and deals with apparent questions, such as why objects do not go flying off a spinning earth, why we do not experience winds constantly out of the east as the earth spins, why birds or butterflies have no more difficulty flying west than east, why a dropped ball falls at the base of a tower on a moving earth, and why a cannonball flies the same distance east and west. His explanations hinged on the idea that the earthbound bodies share a common motion and seem to move only relatively to one another. On day 3, Galileo moves on to consider the heliocentric system and the annual motion of the earth around the sun. Among an array of arguments in favor of Copernicanism and heliocentrism, Galileo introduces the phases of Venus. Seen through a telescope, Venus changes its shape like the earth's moon: a new Venus, a quarter Venus and a "horned" Venus. The upshot of Galileo's technical point is that the observed phases of Venus are incompatible with the geocentric Ptolemaic system. Finally, on day 4 of the Dialogue, Galileo offers what in his own mind represents positive proof of the Copernican system: his idiosyncratic account of the tides. His explanation: a spinning, revolving earth induces sloshing motions in the seas and oceans, and thereby causes the tides. He gives an elegant mathematical explanation for seasonal variations in tides and introduces William Gilbert's work concerning the earth as a giant magnet (McClellan \& Dorn, 2006).

In February 1633, Galileo Galilei was ordered to Rome. The Inquisition found Galileo guilty of "vehement suspicion of heresy", just a notch below conviction for heresy itself, for which punishment was immediate burning at the stake. Galileo's Dialogue was put on the Index of Prohibited Books and on June 22, 1633, this once-proud scientist, kneeling in a public ceremony dressed in the white gown of the penitent, candle in hand, was forced to "abjure, curse and detest" the Copernican heresy and promise to denounce all such heretics. Galileo remained a formal prisoner of the Inquisition under house arrest for life.

After his conviction Galileo decided to concentrate on the sciences of mechanics and hydrodynamics. This led to his book Discourses and Mathematical Demonstrations Concerning two new sciences (1638), usually referred to either as the Discorsi or as Two New Sciences. This book was also written in the form of a dialogue among the same three characters as his previous Dialogue. Galileo used these books to introduce a new method that combines reason, mathematics and experiment into the extremely capable research tool we use in physics to this day (Cassidy et al., 2002). With these books, he tells us the story of the discovery of the language spoken by nature and the ways in which we can question her (Koyre, 1943). Galileo recognized the importance of this new method and pre- 
dicted that it would be used by future scientists, having his alter ego Salviati proclaim in Two New Sciences: "We may say the door is now opened, for the first time, to a new method fraught with numerous and wonderful results which in future years will command the attention of other minds". For liberal minds, the action of the Inquisition against Galileo has become a symbol of the illegitimate exercise of authority over freedom of thought, as well as an unforgivable injustice against an old man whose only crime was an over-fondness for his own harmless ideas. Apologists for the prosecution reply that, because Galileo violated an injunction issued directly to him not to hold or teach ideas he subsequently defended most persuasively, he was rightly suspected of heresy. The Inquisition had either to proceed against him or suffer a loss of authority.

\section{The Educational Program}

\subsection{The Purpose of the Educational Program}

This research aims to introduce HOS by means of authentic historical texts into non-formal science education in order to enhance students' awareness of the cultural aspects of science and the socio-cultural milieu that may affect scientific research. We propose an interactive narrative based on Galileo's Dialogue. Even though Galileo was one of the first and most prominent scientists to introduce and support the mathematical description of natural phenomena, the conceptual experiments he describes in Dialogue can be grasped easily by a wide range of age-groups without the need for a scientific background.

\subsection{The Educational Material}

Galileo and his work have inspired authors (Brecht, 1974) and science educators (Tselfes \& Paroussi, 2009; Allchin, 2012; Stefanidou, 2019). The educational activity presented in this study, which is an interactive narrative, is based on Galileo's (1632/2001) Dialogue and Brecht's (1974) play Life of Galileo. We chose the arguments/episodes to develop primarily on the basis of their amenability to adaptation and active presentation. We tried to avoid episodes that required any special cognitive background, preferring those that relied on everyday experience and served all ages.

The interactive narrative began with a small introduction in which Galileo's life, his achievements and the difficulties he faced were presented in the context of $16^{\text {th }}$-century Europe. Subsequently, a dialogue in the form of an interactive narrative was developed between Galileo's two conflicting characters: Salviati and Simplicio.

The dialogue consists of three sections, in each of which an argument is revealed. The core of the first two arguments is the theme of the motionless earth, while the third argument relates to Jupiter's satellites. All three arguments seek to inform the audience about the nature, content and context of the conflict between the Ptolemaic (geocentric) and Copernican (heliocentric) systems.

The first scene has its origins in Brecht's (1974) Life of Galileo. The geocentric 
view presented by Simplicio is that the Sun cannot be motionless because we can see it moving in the sky. This thought is based completely in empirical data and therefore understandable, but Salviati turns it down. By getting two students from the audience involved, the Earth and the Sun, he shows that if the Sun stands still and the Earth rotates around its axis while orbiting, it sees the Sun moving even though it isn't. The argument is not powerful enough to persuade Simplicio, who reverses the roles to offer evidence that the Earth is not necessarily moving.

Salviati continues the discussion by highlighting the "laziness" of nature, meaning that when something can happen in more than oneway, nature chooses the one that requires less energy. Unable to refute this argument, Simplicio invokes Aristotle's work and authority to support his point of view. After that, there is a dispute between the two characters with Salviati arguing that even though Aristotle's work is remarkable, that does not mean he was never wrong, nor that we should take his words to be true without proof. However, at the end of the clash, Simplicio prevails by demonstrating that the Catholic Church and the Inquisition support Aristotle and his geocentric views, with Salviati backing down out of fear.

In his attempt to persuade Simplicio that he is not questioning the Church's point of view, Salviati presents an argument that supports the immobility of the Earth, setting a trap for Simplicio. This argument was selected for historical reasons, as it was the most powerful argument against a moving Earth. Once Salviati has presented all the reasons why it should be accepted, he took it apart. In his book, Galileo uses this technique more than once, showing that Salviati has carefully studied and rejected the core tenets of geocentrism, while Simplicio remains completely unaware of the arguments in favour of heliocentrism. Thus, it was believed that if the Earth rotated, if an object were dropped, it would fall to the ground closer to the west than its initial position, since the Earth would rotate below it. Having presented this statement to Simplicio, Salviati proves it wrong by explaining the role of the object's initial velocity.

In order to make this argument more intelligible, along with a drawing of a tower with a stone falling, the motion was represented bodily. Specifically, Salviati with a book in his hands starts to rotate around his axis, representing the Earth. While he is rotating, he lets go of a pencil which falls onto the book. In his effort to understand this simple experiment, Simplicio repeats it, holding the pencil and showing its trajectory in slow motion.

After Simplicio has admitted-barely-that Salviati's explanation is plausible, Salviati continues the dialogue by presenting his final argument: introducing the telescope to the audience, he presents a drawing from Galileo's notebook showing Jupiter and some of its satellites. After a discussion with the students about Jupiter's satellites and the observed changes in their positions, the two interlocutors end up concluding that they are orbiting Jupiter. In order to reach this conclusion, Salviati also represents the motion of one satellite with the help of a student. By showing some celestial objects that orbit Jupiter, Salviati rejects the 
geocentric statement made previously by Simplicio that every celestial body orbits the motionless Earth.

The dialogue/narrative ends with Simplicio having doubts; partly because he is not receptive to new ideas that opposite his beliefs and partly because the arguments presented were limited in number and insufficiently convincing. The narrative closes with a short epilogue which continues Galileo's story after the publication of the book. Finally, a discussion takes place motivated by the epilogue's final sentence, which is Newton's famous phrase: "If I have seen further, it is by standing on the shoulders of giants".

\subsection{The Implementation}

The implementation took place during the 2018-2019 academic year in the context of the participation of the University of Athens Department of Education in the Athens Science Festival (2019). The general context includes a drama group consisting of four university students from the University of Athens' Department of Physics who worked on adapting the scenario and directing the three performances. The preparations lasted for four months from December 2018 to April 2019 and were coordinated by the first author.

The audience consisted of 75 students, separated into three groups. In the first phase of the project, the activity was presented in a class ( 25 students) during a visit to the $2^{\text {nd }}$ Experimental Secondary School of Athens in a pilot context. In the second phase, the project was carried out at the Athens Science Festival (2019) at Technopolis, City of Athens, which one class (25 students) of junior high school students and one class (25 students) of high school students attended (http://www.athens-science-festival.gr/en/event/and-yet-it-moves/).

Every performance lasted about half an hour, the final duration depending on the students' participation. Students participated either by representing a phenomenon or by expressing their opinion on a given explanation. Figure 2 reveals the performance set-up.

During the first argument about the motion of the earth, at least two students were called upon to represent the earth and the sun by carrying a ball and wearing a paper construction respectively (Figure 3). Salviati, who is the third person in Figure 3, guided them in order to reveal that the earth rotates around the sun and asked for their consent.

In Figure 4, Salviati conducts an experiment using his pen and his book to explain the motion of a falling body on a rotating earth.

In Figure 5, Salviati explains to Simplicio that there are some bodies that rotate around Jupiter in the same way our moon rotates around the earth, trying to convince him that there is nothing special about the earth and that the so-called "celestial spheres" do not exist.

Students were eager to participate, with the high school students proving more active than the junior high school students. In the conversation initiated by Newton's phrase at the end of the activity, the students stated that Newton was 


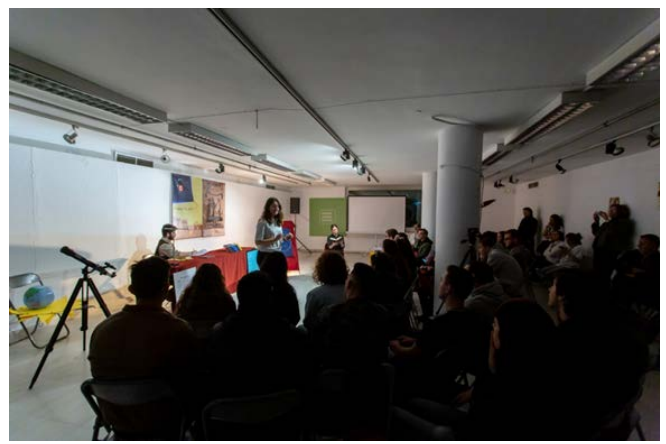

Figure 2. The performance took place in Technopolis (Athens on $4^{\text {th }}$ April 2019).

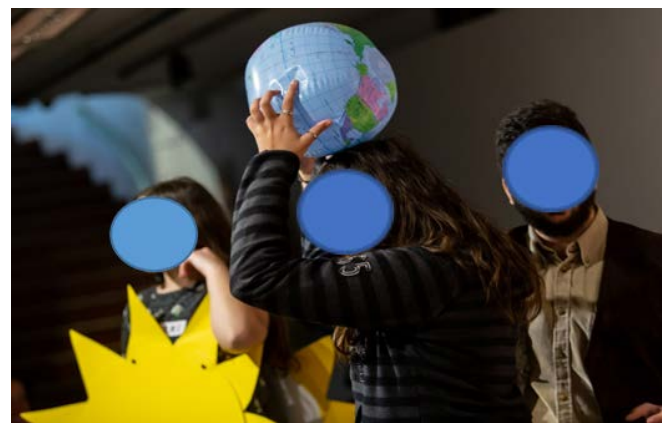

Figure 3. Students representing the Sun and the Earth (Athens, $4^{\text {th }}$ April 2019).

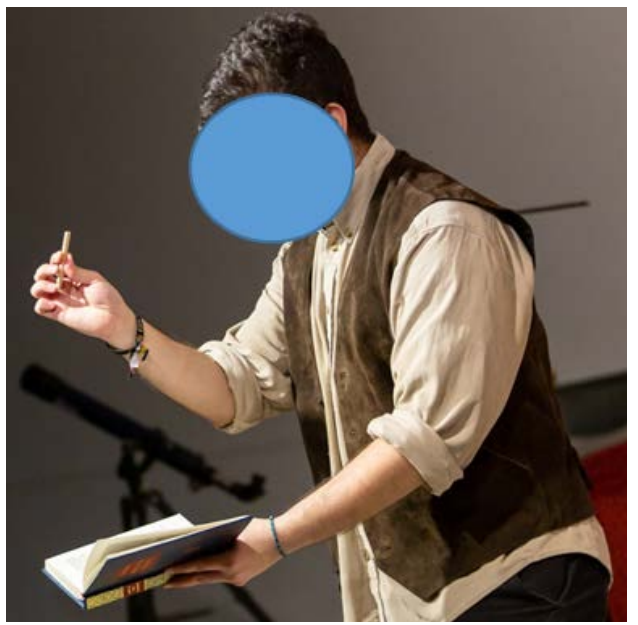

Figure 4. Salviati explains the motion of his pen in a rotating earth (Athens, $4^{\text {th }}$ April 2019).

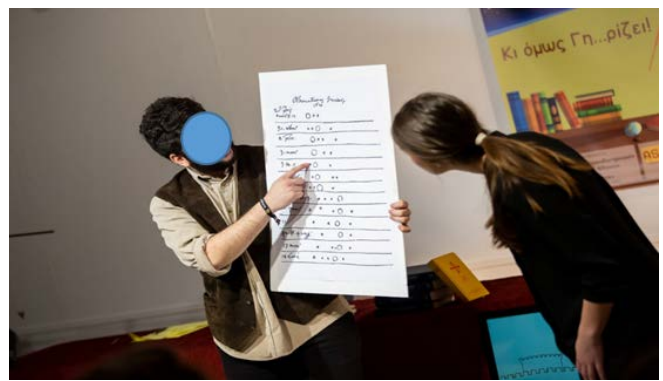

Figure 5. Salviati explains to Simplicio that Jupiter has its own moons (Athens, $4^{\text {th }}$ April 2019). 
talking about scientists who had existed prior to him, and that without their work he would not have been able to contribute so much to the development of science. They also realized the importance of Galileo's work; surprisingly, many already knew about his sentence, even though some interesting guesses were also aired. In addition, it was obvious to them that Galileo's views were contrary to the church's doctrine. Numerous students gradually conceptualized that Galileo doubted more than the church: he doubted the entire worldview of his era. Finally, the activity's title, "And yet it moves!", stimulated a discussion in which the students expressed the opinion that this unverifiable phrase was more legend than fact.

\section{Conclusion and Discussion}

In this paper, an attempt was made to animate the cultural role of science as an institution that produces ideas in a particular social and philosophical context. For this purpose, Galileo's Dialogue, which was written in a language understandable to lay audience, was used. In the same way, we based an activity on Galileo's text which was not aimed at specialists, but rather at secondary and high school students visiting a science festival. Through their participation in the program "And yet ... it moves", they had the opportunity to follow in Galileo's footsteps and get acquainted with such aspects of science as its interaction with society, religion and the ruling class in general.

The implementation of the educational program revealed that HOS can be introduced into informal science education settings such as Science Festivals. Student participants in the project were enthusiastic, posed sophisticated questions and produced answers relating to the socio-cultural milieu of science. They also directly expressed their amenability to future participation. There is strong evidence that HPS, apart from enhancing scientific literacy in the context of formal education, can also offer out-of-school experiences to young audiences. Taking into consideration the limitations of the present educational program, provided the limited audience, the absence of a robust methodology in order to test students attitudes towards science and the extent to which they actively participated in the program along with the fact that we had no feedback from their science teachers and laypeople, the present project calls for further study and implementation.

Particularly, further fieldwork is suggested in order students' interests, attitudes, previous knowledge and new knowledge to be better estimated in terms of improving HPS-based educational material for science festival demonstration and beyond. Here the issue of interaction between formal and informal science education in the context of HPS emerges, which is worth investigating, too.

What seems to be important for future research is to investigate in-service science teachers' views on such programs, what encourages and what discourages them from participating. Such an attempt could include their participation in interactive narratives designed specifically for science teachers, during which 
they could express their doubts and ideas and enhance their knowledge on HPS issues.

Moreover, further implementation with adult audiences is also suggested. In this case, it would be very interesting to update the socio-political constraints of science so that the adult audience engages not only with the historical dimension of science, but also with its corresponding contemporary version. Following in Galileo's footsteps, adult audiences would have the opportunity to familiarize themselves with aspects of science that, though are not very popular, nonetheless constitute an aspect of scientific literacy.

\section{Acknowledgements}

The authors would like to thank Katerina Vavouraki, Clio Milioni and Stefanos Katsiantonis for their valuable contributions to the scenario, direction and performance of the present project.

\section{Conflicts of Interest}

The authors declare no conflicts of interest regarding the publication of this paper.

\section{References}

Allchin, D. (2012). Teaching the Nature of Science through Scientific Errors. Science Education, 96, 904-926. https://doi.org/10.1002/sce.21019

Athens Science Festival (2019). http://www.athens-science-festival.gr/en/event/and-yet-it-moves

Brecht, B. (1974). The Life of Galileo. London: Methuen Publishing Ltd.

British Science Association (2019). https://www.britishscienceassociation.org/pages/faqs/category/past-british-science-fest ivals

Brush, S. G. (1989). History of Science and Science Education. Interchange, 20, 60-70. https://doi.org/10.1007/BF01807048

Cassidy, D., Holton, G., \& Rutherford, J. (2002). Understanding Physics. New York: Springer-Verlag. https://doi.org/10.1007/b97394

Chasapi, E. (2018). The Role of History and Philosophy of Science in Science Teaching: A Research in Related Journals of the Period 2000-2017. Master Thesis, Patra: Hellenic Open University.

Daston, L. (2000). Biographies of Scientific Objects. Chicago, IL: University of Chicago Press.

Drake, S. (1957). Discoveries and Opinions of Galileo, Translated with an Introduction and Notes. Garden City, NY: Doubleday \& Company Inc.

Drake, S. (1973). Galileo's Language: Mathematics and Poetry in a New Science. Yale French Studies, 49, 13. https://doi.org/10.2307/2929564

Einstein, A. (1953/2001). Foreword G. Galilei, Dialogue Concerning the Two Chief World Systems (pp. 23-29). New York: Modern Library Science Series (Original Work Published 1632).

Eshach, H. (2007). Bridging In-School and Out-of-School Learning: Formal, Non-Formal, 
and Informal Education. Journal of Science Education and Technology, 16, 171-190. https://doi.org/10.1007/s10956-006-9027-1

EUSCEA (2005) White Book on Science Communication Events in Europe. Vienna: European Science Events Association.

Fensham, P. J. (1997). School Science and Its Problems with Scientific Literacy. In R. Levinson, \& J. Thomas (Eds.), Science Today: Problem or Crisis (pp. 119-236). London: Routledge.

Filippoupoliti, A., \& Koliopoulos, D. (2014). Informal and Non-Formal Education: An Outline of History of Science in Museums. Science \& Education, 23, 781-791. https://doi.org/10.1007/s11191-014-9681-2

Galilei, G. (1632/2001). Galileo Galilei: Dialogue Concerning the Two Chief World Systems. New York: Modern Library Paperback Edition.

Galison, P., \& Thompson, E. (1999). The Architecture of Science. Cambridge, MA: MIT Press.

Golinski, J. (1998). Making Natural Knowledge: Constructivism and the History of Science. Cambridge: Cambridge University Press.

Hodson, D. (2008). Towards Scientific Literacy. Rotterdam: Sense Publishers. https://doi.org/10.1163/9789087905071

Jensen, E., \& Buckley, N. (2012). Why People Attend Science Festivals: Interests, Motivations and Self-Reported Benefits of Public Engagement with Research. Public Understanding of Science, 23, 557-573. https://doi.org/10.1177/0963662512458624

Karolides, N., Bald, M., \& Sova, D. (2011). 120 Banned Books Censorship Histories of World Literature. New York: Checkmarks Books.

Koyre, A. (1943). Galileo and Plato. Journal of the History of Ideas, 4, 400. https://doi.org/10.2307/2707166

Malcolm, J., Hodkinson, P., \& Colley, H. (2003). The Interrelationships between Informal and Formal Learning. Journal of Workplace Learning, 15, 313-318. https://doi.org/10.1108/13665620310504783

Matthews, M. (2015). Science Teaching: The Contribution of History and Philosophy of Science, 20th Anniversary Revised and Expanded Edition (2nd ed.). New York: Routledge. https://doi.org/10.4324/9781315811642

McClellan, J., \& Dorn, H. (2006). Science and Technology in World History. Baltimore, MD: The Johns Hopkins University Press.

National Research Council (1996). National Science Education Standards. Washington DC: National Academy Press.

Riise, J. (2012). Science Festivals. In R. Gunstone (Ed.), Encyclopedia of Science Education (pp. 1-2). Dordrecht: Springer. https://doi.org/10.1007/978-94-007-6165-0 328-4

Sequeira, M., \& Leite, L. (1991). Alternative Conceptions and History of Science in Physics Teacher Education. Science Education, 75, 45-56.

https://doi.org/10.1002/sce.3730750105

Seroglou, F., \& Koumaras, P. (2001). The Contribution of the History of Physics in Physics Education: A Review. In F. Bevilacqua, E. Giannetto, \& M. R. Matthews (Eds.), Science Education and Culture (pp. 327-346). Dordrecht: Springer.

Skordoulis, C., \& Stefanidou, C. (2011). Epistemological Aspects of the Historiography of Science in Greece. Organon, 43, 29-47.

Stefanidou, C. (2019). History and Philosophy of Science for Citizenship: The Case of Life of Galileo by Bertolt Brecht. In P. Heering (Ed.), Science as Culture in the European 
Context (pp. 77-100). Flensburg: Flensburg University Press.

Stefanidou, C., \& Skordoulis, C. (2014). Subjectivity and Objectivity in Science: An Educational Approach. Advances in Historical Studies, 3, 183-193.

https://doi.org/10.4236/ahs.2014.34016

Stefanidou, C., \& Skordoulis, C. (2017). Primary Students Teachers' Understanding of Basic Ideas of Nature of Science: Laws, Theories and Models. Journal of Studies in Education, 7, 127-153. https://doi.org/10.5296/jse.v7i1.10599

Tselfes, V., \& Paroussi, A. (2009). Science and Theatre Education: A Cross-Disciplinary Approach of Scientific Ideas Addressed to Student Teachers of Early Childhood Education. Science \& Education, 18, 1115-1134. https://doi.org/10.1007/s11191-008-9158-2

Van Praet, M. (1995). Les expositions scientifiques miroirs épistémologiques de l'évolution des idéesen sciences de la vie. Bulletin d'Histoire et d'Epistémologie des Sciences de la Vie, 2, 52-69. 